\title{
How Does Emigration Affect Labor Markets? Evidence from Road Construction in Brazil ${ }^{*}$
}

Flávia Chein ${ }^{* *}$

Juliano J. Assunção***

\begin{abstract}
We study the impact of emigration on local labor markets, based on the construction of a 1,087-km road in northeastern Brazil. The new road has changed population density substantially, creating new towns along its path and increasing internal migration flows. We first use a reduced-form approach to estimate the effect of emigration on skill groups (defined by education and experience) - a 10 percentage point increase in the proportion of emigrants (which denotes a fall in labor supply) raises wages by $5 \%$. Then, by using a structural approach, we estimate elasticities of substitution across types of labor and between capital and labor. Based on these estimates, we calculate the price elasticities and wage effects among groups - although emigration typically raises wages, complementary effects determine negative impacts on some municipalities. On average, we estimate an overall increase of $50 \%$ in local wages due to the construction of the road.
\end{abstract}

Keywords: Migration, Roads, Labor supply, Competitive local markets, Elasticities of substitution, Wage effects.

JEL Codes: J31, O15, O18.

\footnotetext{
${ }^{*}$ Submitted in March 2015. Revised in May 2016. The authors are thankful to CNPq and Fapemig.

** Department of Economics, Federal University of Juiz de Fora, Brazil.

E-mail: flavia.chein@ufjf.edu.br

${ }^{* * *}$ Department of Economics, PUC-Rio, Brazil. E-mail: juliano@econ.puc-rio.br
}

Brazilian Review of Econometrics

v. $36, \mathrm{n}^{\mathrm{o}} 2$, pp. $157-184 \quad$ November 2016 


\section{Introduction}

In 1976, the Brazilian government constructed a 1,087-km road from Belém to Teresina that established an important link between the north and the northeast regions of the country. The road construction was followed by concentration of the population and creation of new municipalities. ${ }^{1}$ According to the 1980 Demographic Census, the size of migration flows to the municipalities in a radius of $200 \mathrm{~km}$ around the road increased by $50 \%$ after its construction, with originations predominantly coming from within this radius. Additionally, the number of municipalities along the road increased from 32 in 1976 to 66 in 2000, which is substantially more than the $10 \%$ increase observed in the rest of the country.

As documented recently, major roads affect the distribution of the population (Baum-Snow, 2007a,b, Duranton and Turner, 2007, Morten and Oliveira, 2014b,a) and labor markets (Michaels, 2008, Morten and Oliveira, 2013). Here, our focus relies on the emigration flows induced by the new road connecting Belém to Teresina. Proximity to the road is considered as a means of estimating the effect of emigration on wages: an underdeveloped topic in the literature (Mishra, 2007). The analysis is presented in two parts.

In the first part, we consider migration as a labor supply shock that affects different skill groups (defined in terms of schooling and experience), as indicated in Borjas (2003) and Mishra (2007). We also introduce an additional step and consider migration as endogenous ${ }^{2}$ and use road construction as a way of improving the empirical identification of the effects of migration on the labor market: distance to the constructed road is used as an instrument for emigration. This additional step of identification matters because an increase of 10 percentage points in the number of emigrants raises wages from $1.44 \%$, using the OLS estimate, to $5.1 \%$, using the IV estimate. The latter represents a wage elasticity of $0.15 \%$, evaluated at the mean value of outmigration shock (29.30\%) in the area of Belém-Teresina.

In the second part of the paper, we specify a production function to study not only the direct effect of a particular emigration flow on the wages of the respective group of non-migrant workers, but also the cross effects on the wages of workers in different skill groups. Following Borjas (2003), we estimate the own-factor price and cross-factor price elasticities (across skill groups). Our results suggest that, although the effect of emigration around the Belém-Teresina road on wages was usually positive, in many municipalities, there was a negative effect on wages for the groups with less than one year of schooling due to a complementary effect.

One limitation of our analysis is the fact that the road construction might have additional effects on wages due to changes in labor demand, like the ones described by Morten and Oliveira (2014b,a). The authors find that a $10 \%$ increase

\footnotetext{
${ }^{1}$ Municipalities are the smallest political and administrative units in Brazil. In size, they are roughly somewhere between US counties and cities.

${ }^{2}$ Roy (1951); Sjaastad (1962); Chiswick (1978, 1999); Banerjee and Kanbur (1981); Borjas (1987, 1999b,a); Chiquiar and Hanson (2005); Mckenzie and Rapoport (2007).
} 
in paved roads increases the wage premium by $0.8 \%$ and the municipal GDP by $0.9 \%$. The changes in transportation costs might affect the demand for the outputs of pre-existing firms, or even change the location of the firms. There are at least two reasons why these effects are not relevant in our case. First, an overall change in the demand for goods in a given municipality would affect all skill groups uniformly, especially if the underlying technology is homothetic, as assumed in our analysis. In this way, variation in emigration across skill groups is more likely to be associated with labor supply rather than with labor demand. Second, we find no evidence that either the levels or the changes in the number of firms or residential capital stock are associated with the distance to the Belém-Teresina road.

We believe that our paper contributes to the literature in at least two directions. First, our empirical environment provides a new instrumental variable approach to estimate the elasticity of labor demand. We consider one additional identification step in comparison to Borjas (2003) and Mishra (2007), which we find to be relevant. Second, our results suggest that the construction of a road affects not only the labor markets along its path, as in Michaels (2008), but also the labor markets in municipalities not directly affected by such improvement. In this sense, it is important to note that our paper focuses on markets that lose workers to areas near the road instead of on markets with productivity gains from the new road. We exploit the fall of migration costs as an effect of connecting more places by roads, as described by Morten and Oliveira (2013, 2014b,a).

The remainder of the paper is organized as follows. Section 2 presents the Belém-Teresina road. Section 3 describes the database. Section 4 discusses the impacts of the road on the regional labor market. Section 5 presents a structural approach. Section 6 discusses some limitations and caveats. Section 7 concludes.

\section{The Belém-Teresina Road}

The Belém-Teresina road was built in the 1970s as a part of the national policy for integration and development of the country as a whole. The highway, which comprises stretches of BR-316 and BR-010, is an important link between the north and northeast regions of the country. It was opened to traffic in 1976, with 1,087 kilometers of paved road. Along with the Belém-Brasilia road, the Belém-Teresina road was the main access route to East Amazônia at that time. It also provides access by land from coastal municipalities in the northeast to waterways in the north (Sant'anna, 1988).

Figure 1 depicts an area of 200 kilometers that surrounds the Belém-Teresina road, which is the focus of our analysis. The road crosses a very poor region, where a large percentage of the municipalities was mostly rural until the $1990 \mathrm{~s}$; $58 \%$ of the population aged over 10 years was living in rural areas in 1980 . Note that we excluded the state capitals (Belém, Teresina, and São Luis), and all the municipalities the road passes through, from our sample. This is because we are primarily interested in the effect of emigration. 
Figure 1

Area surrounding the Belém-Teresina road

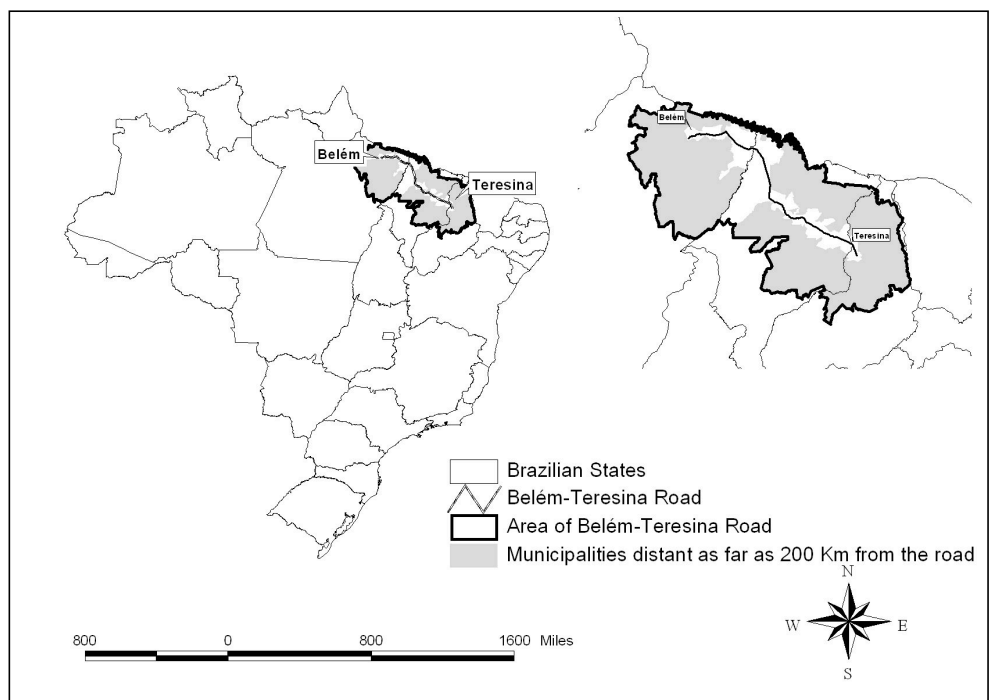

Source: Author's elaboration based on IBGE Digital Maps.

The construction of the Belém-Teresina road has increased the population density along its path. This change can be seen in two dimensions - creation of new towns and migration flows.

Figure 2 shows the increased urban agglomeration and the creation of new towns after the construction of the Belém-Teresina road. Between 1970 and 2000, the number of municipalities in the area surrounding the road increased by $50 \%$, from 218 to 344 towns, compared to an average increase of $10 \%$ for the whole country.

There was also a redistribution of the population in the road's area. Figure 3 shows that the number of migrants increased after the road was completed and that most of this flow is internal, coming from municipalities within the referred area. There was an important inflow of migrants to areas near the road. This is the main reason why we focus our analysis on the impact of emigration.

Figures 4 and 5 show the emigration flows of different experience and education groups, respectively, for the years 1980 and 1991, as a a function of the distance to the road. Each curve represents locally weighted regressions, with least-squares smoothing and a bandwidth of 0.8 , and considers a sample of migration groups within each municipality in the road's area.

The overall pattern is that not only do the levels of the flows decrease with the distance, but that the same is true for the changes between 1980 and 1991. 
Figure 2

New towns in the area surrounding the Belém-Teresina road in 1970 and 2000

Area Surrounding the Belém-Teresina Road

1970

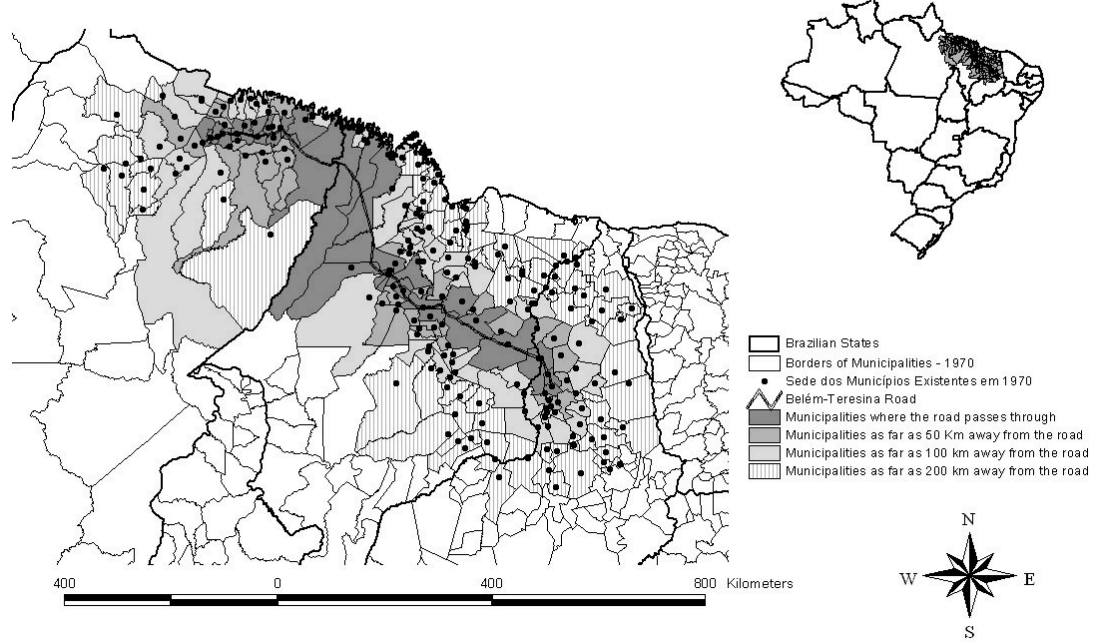

Area Surrounding the Belém-Teresina Road

2000

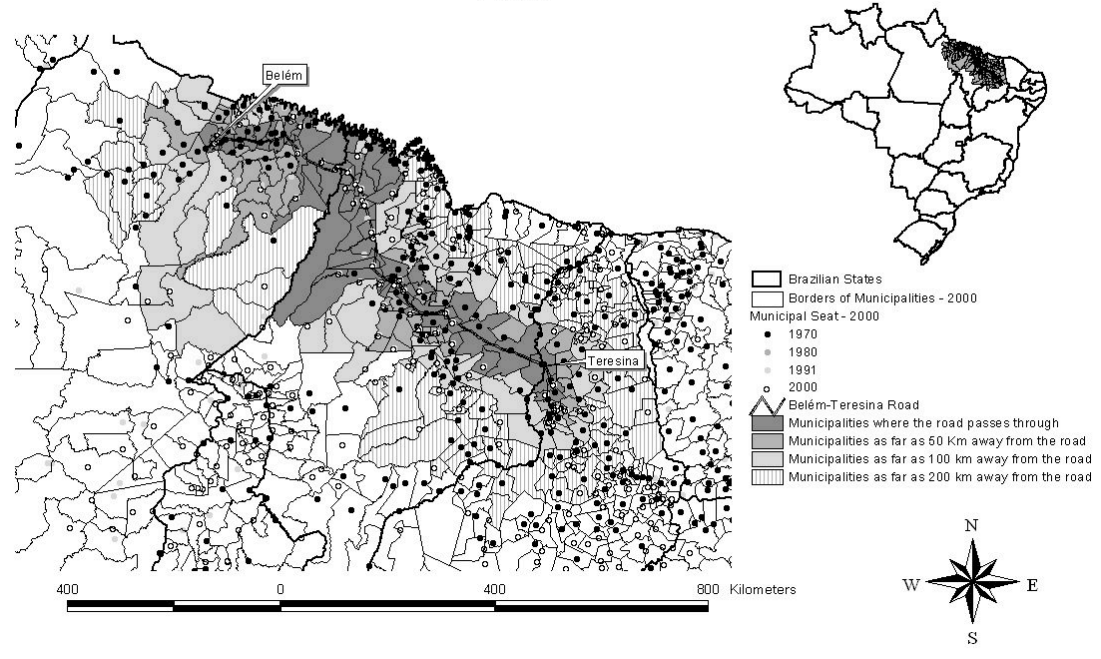

Source: Author's elaboration based on IBGE Digital Maps. 
Figure 3

Immigration in the area surrounding the Belém-Teresina road in 1980 Internal versus External Migration

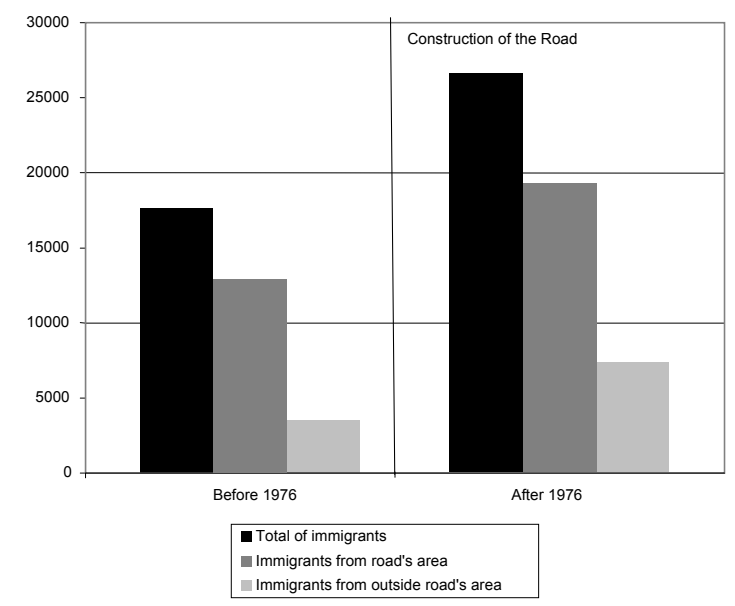

Source: Author's elaboration based on IBGE Digital Maps.

Figure 4 shows that individuals with 6 to 15 years of experience are the group with the largest flow of emigrants for both years. There is a positive increase in the number of emigrants for all the experience groups that decreases with the distance to the road and is higher for the two groups with less experience.

Figure 5 shows that the emigration flows for individuals with less than four years of schooling sharply decrease with the distance to the road. The pattern for the most educated is less clear, although the change also decreases with the distance. The changes for the group with less than one year of schooling are negative, although relatively low in comparison with the other levels.

In summary, the construction of the road induced an important change in the location of the population in the 200-km surrounding area. This change is systematically related to the distance to the road. By analyzing a large expansion of road infrastructure in Brazil, Morten and Oliveira (2014b) point out that, after controlling for the Euclidean distance between two locations, reducing the road distance by $50 \%$ would increase migration rates by $40 \%$, but the the effect of the road infrastructure on migration is reduced by $10 \%$ once the general equilibrium effects of migration are computed. In the following sections, we use the construction of the Belém-Teresina road as a means of identifying changes in the labor supply determined by emigration. 
Figure 4

Emigration and distance to the road per experience groups

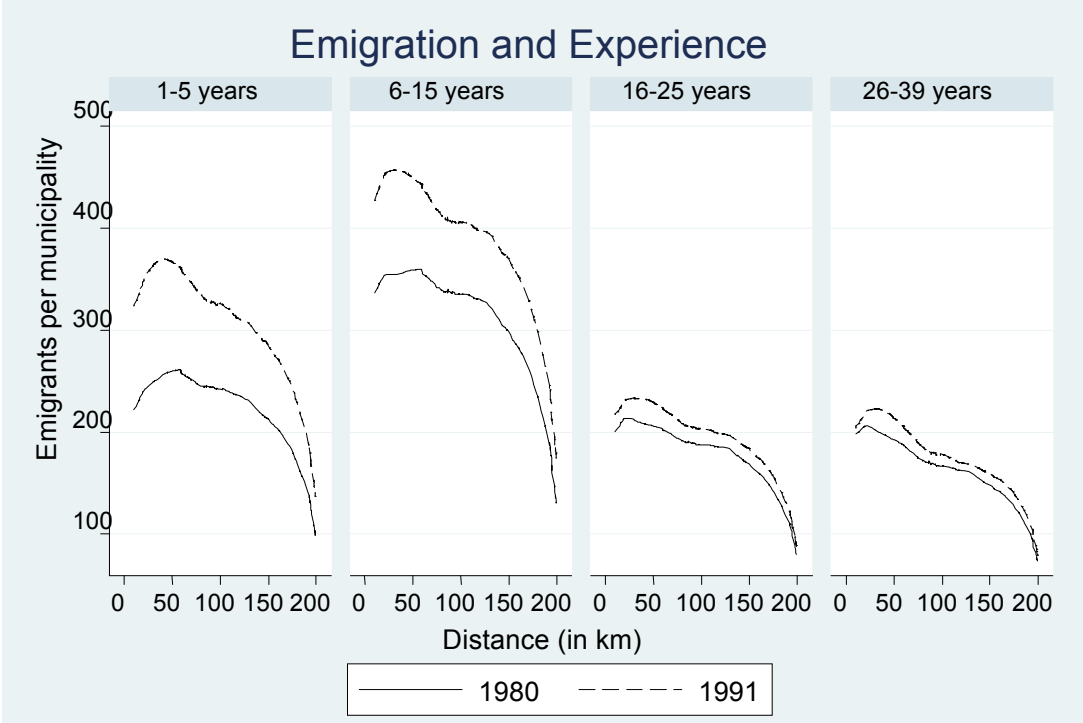

Source: Demographic Census of 1980 and 1991.

Emigration and distance to the road per education groups

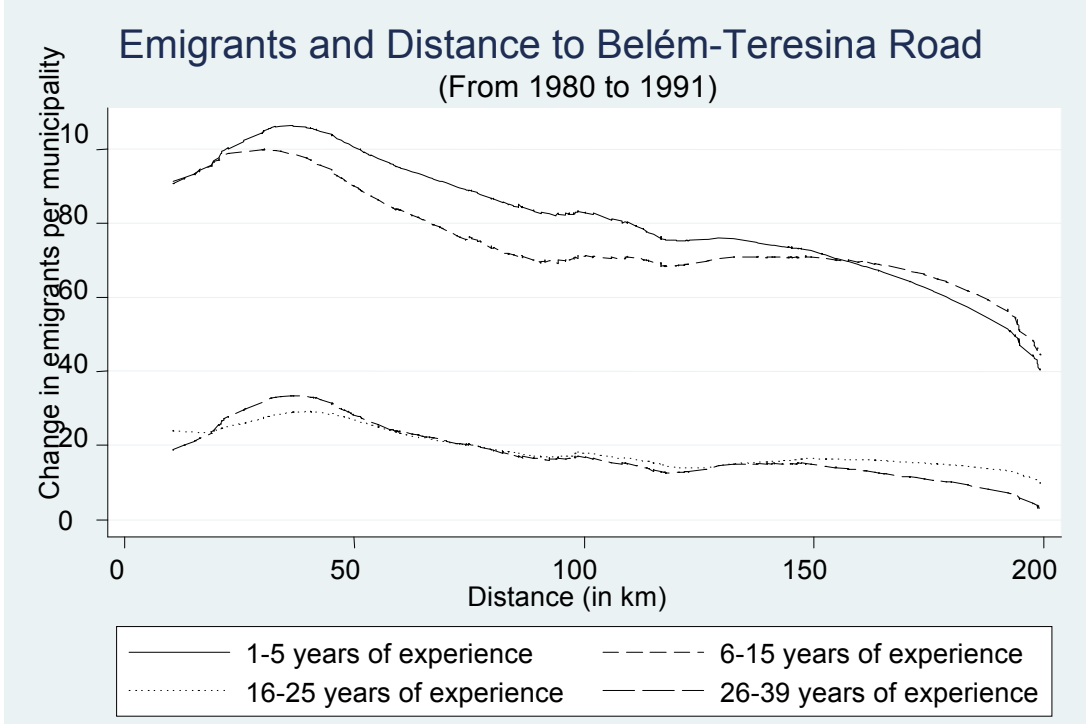

Source: Demographic Census of 1980 and 1991. 
Figure 5

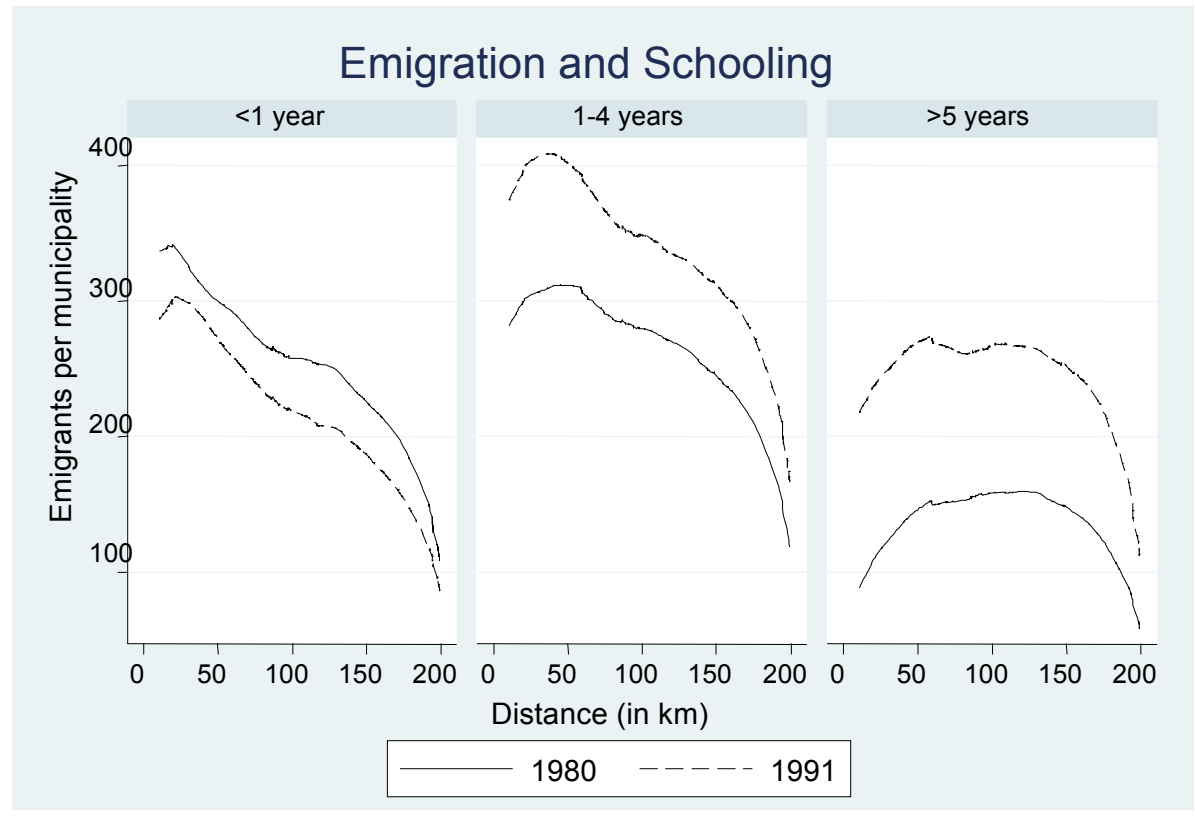

Source: Demographic Census of 1980 and 1991

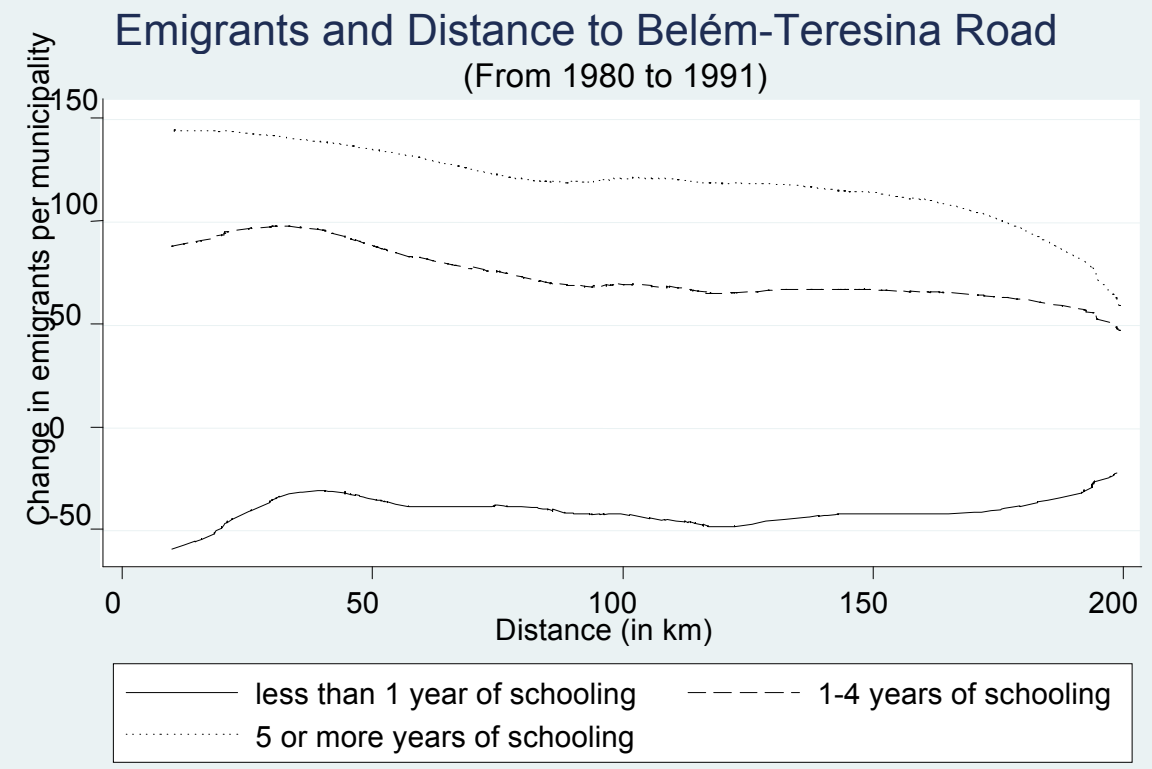

Source: Demographic Census of 1980 and 1991. 


\section{Data}

We use data from the 1980 and 1991 demographic censuses, collected by the Brazilian Institute of Geography and Statistics (IBGE). Along with the basic information collected for the Census, IBGE also used an extended questionnaire to obtain more detailed socioeconomic information. This extended questionnaire is applied to a sample of 10 to $15 \%$ of the population of each municipality, depending on its size. Our data come from this longer survey.

We work with a subsample of workers with between 1 and 39 years of experience who live in the areas around the Belém-Teresina road. The two years of data represent repeated cross-sections, because it is not possible to track individuals across the surveys.

Although we are interested in the area surrounding the Belém-Teresina road, we use information from the whole country to account for migration. We have tracked all migrants who have left a municipality in our area of analysis to settle themselves in another municipality within the country. Unfortunately, it is not possible to consider international migration outflows in our analysis. But this is not likely to be a problem because international migration is not quantitatively relevant in Brazil and, moreover, we are considering a very poor region with extremely low levels of international migration flows.

Migrants in our sample are those whose Census records indicate they were settled in another municipality in a 10-year window. Thus, migrants in the 1980 Census are those who migrated in the 1970s, while migrants in 1991 consist of those who moved during the 1980s.

Table 1 presents the distribution of non-migrants, immigrants, and emigrants across many categories for 1980 and 1991, while Table 2 depicts the averages for experience, years of schooling, and earnings in areas surrounding the BelémTeresina road. The comparative analysis between migrants and non-migrants reveals differences in many dimensions. Compared to non-migrants, immigrant flows are comprised of more women, a higher proportion of individuals aged 20-29 years, more educated workers with less experience, people from urban areas, fewer individuals declared as self-employed, and more employees with higher income and hours worked. The same is true for emigrants, although we can see differences between immigrants and emigrants, i.e., the place of residence for emigrants is more frequently in urban areas. The differences are also qualitatively the same across the years.

\section{A Reduced-Form Approach}

Emigration is considered in our framework as a labor supply shifter to estimate wage effects or "wage elasticities" in the municipalities influenced by the BelémTeresina road. We start our analysis with a reduced-form approach, based on a Mincerian wage equation. We first consider an OLS estimation, where emigration 


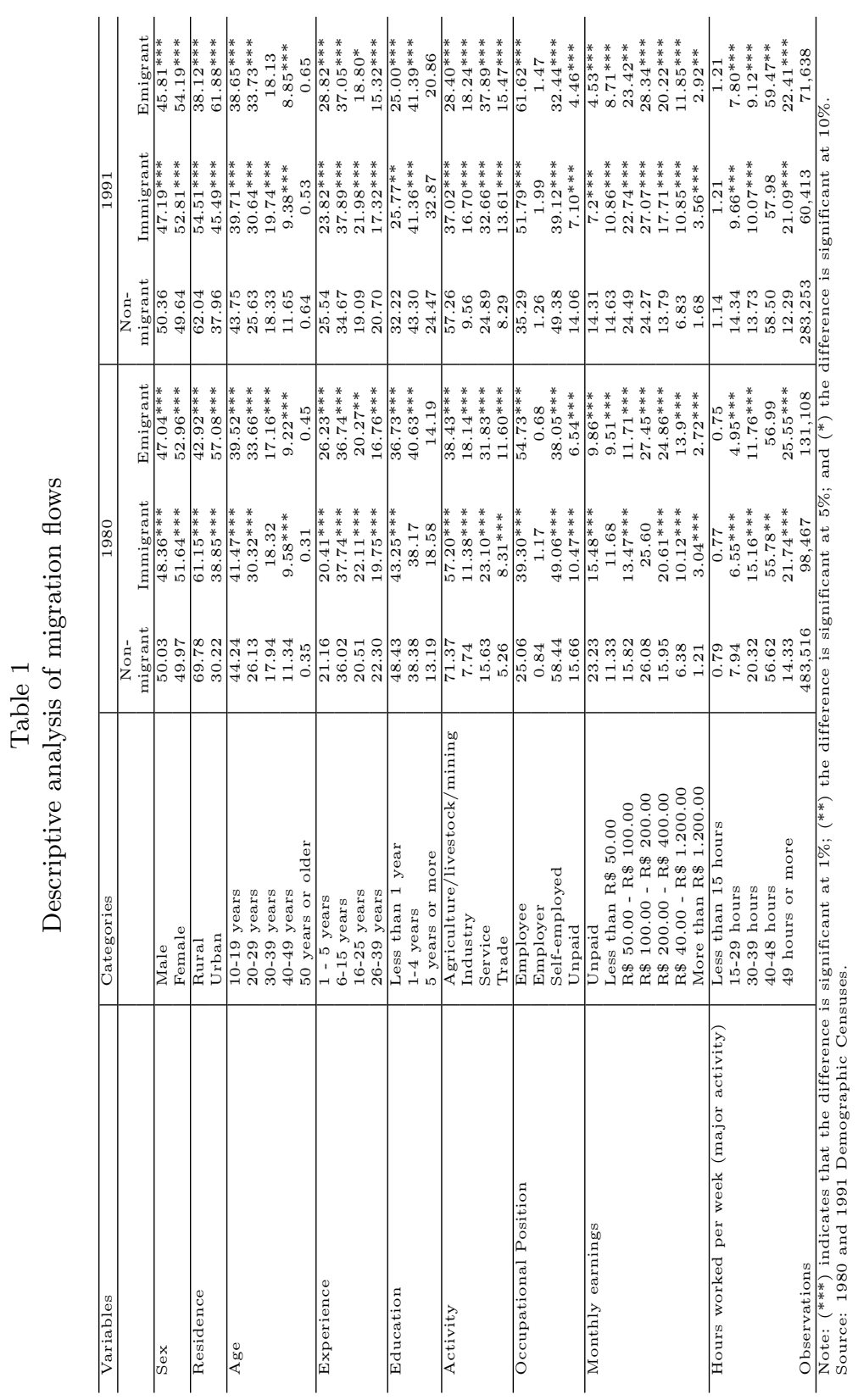


Table 2

Comparative analysis between migrants and non-migrants

\begin{tabular}{llll}
\hline \multicolumn{4}{c}{ Areas Surrounding the Belém-Teresina Road } \\
\hline Variables & Group & 1980 & 1991 \\
\hline Average Experience & Non-migrant & 14.88 & 14.14 \\
& Immigrant & $14.44^{* * *}$ & $13.6^{* * *}$ \\
& Emigrant & $13.95^{* * *}$ & $13.26^{* * *}$ \\
\hline Average Years of Schooling & Non-Migrant & 2.06 & 3.17 \\
& Immigrant & $2.56^{* * *}$ & $3.85^{* * *}$ \\
& Emigrant & $2.97^{* * *}$ & $3.87^{* * *}$ \\
\hline Average Monthly Earnings & Non-Migrant & 76.05 & 177.86 \\
(R $\$ 2.000)$ & Immigrant & $119.02^{* * *}$ & $267.68^{* * *}$ \\
& Emigrant & $136.09^{* * *}$ & $257.74^{* * *}$ \\
\hline Average Age & Non-Migrant & 23.74 & 24.02 \\
& Immigrant & $23.79^{* * *}$ & $24.18^{* * *}$ \\
& Emigrant & $23.92^{* * *}$ & $24.13^{* * *}$ \\
\hline Note: (***) indicates that the difference is significant at 1\%; & \\
(**) the difference is significant at 5\%; & & \\
and $(*)$ the difference is significant at 10\%. & & \\
Source: 1980 and 1991 Demographic Censuses. &
\end{tabular}

is taken as exogenous. We then extend our analysis to introduce the possibility of endogenous migration and consider that road construction is a source of exogenous variation in migration.

\subsection{Specification}

Following Borjas (2003) and Mishra (2006), we start with a very simple approach of regressing the individual logarithm of wages in source economies on the variable related to emigration that controls for individual and municipality characteristics. The specification is given by:

$$
\ln w_{s i t}^{I}=\beta_{0} m_{s i t}+\beta_{1}^{\prime} Z_{i}+\beta_{2}^{\prime} X_{s i t}^{I}+\nu_{s}+\pi_{t}+\left(\nu_{s} * \pi_{t}\right)+\varepsilon_{s i t}^{I}, 1
$$

where $w_{s i t}^{I}$ is the monthly earnings for individual $I$, in period $t$, who belongs to skill group $s$ and lives in municipality $i$; the $m_{s i t}$ is the ratio of emigrants to natives (those who have lived in the municipality for 10 years or more) in skill group $s$, municipality $i$, and year $t$; the $Z_{i}$ is a vector of municipality characteristics (distance to state capitals, altitude and distance to the coast) $;^{3}$ and the $X_{\text {sit }}^{I}$ is a vector of individual characteristics (gender, age, experience, education, marital status, occupation, and activity, among others). We also include group fixed effects $\left(v_{s}\right)$, time fixed effects $\left(\pi_{t}\right)$, and their interactions $\left(v_{s} * \pi_{t}\right)$ to account for unobserved and possible time-varying characteristics of the skill groups. Also, we incorporate the possibility of having the residuals $\varepsilon_{s i t}^{I}$ correlated within each cell defined by group, municipality, and year by adjusting the variance for clustering at the group-municipality-year level.

\footnotetext{
${ }^{3}$ All distance variables are built based on a geoprocessing software. In the case of the distance between two municipalities, we consider the spherical distance between the seats. The distance from a city to the coast uses as a reference the nearest municipal seat on the coast.
} 
We first consider an OLS estimation of equation (1). However, this strategy can lead to inconsistent estimates if emigration is affected by other wage determinants. In fact, the migration literature stresses that migration flows usually respond to wage differentials, among other factors (Roy, 1951, Sjaastad, 1962, Greenwood, 1975, Borjas, 1987, 1999a, Kanbur and Rapoport, 2005). Under the assumption that individuals living in municipalities with lower wages have a higher probability of emigrating, municipalities with worse labor market conditions for a skill group $s$ might depict a higher proportion of emigrants in that skill group. In this case, the estimated coefficient of $m_{\text {sit }}$ will be downward biased.

In order to account for possible endogeneity between migration and wages, we use the construction of the Belém-Teresina road as a source of exogenous variation in emigration. The road reduces distances between these municipalities and state capitals (Belém and Teresina). The evidence regarding the effect of distance on the migration outflows in the region is clear not only in Figures 4 and 5, but also in the migration literature (Sjaastad, 1962, Sahota, 1968, Schwartz, 1973, Fields, 1979, Carrington et al., 1996). In the case of the Brazilian transport infrastructure, Morten and Oliveira (2013, 2014a) find evidence that access to roads is a significant determinant of migration choice and migration destination. Consequently, it increases wages and reduces the relative wage gap. Thus, we consider a first-stage specification where the proportion of emigrants $m_{s i t}$ is a function of the distance of municipality $i$ to the Belém-Teresina road (represented by $d_{i t}$ ), as follows:

$$
m_{s i t}=\gamma_{0} d_{i t}+\gamma_{1}^{\prime} Z_{i}+\gamma_{2}^{\prime} X_{s i t}^{I}+\nu_{s}+\pi_{t}+\left(\nu_{s} * \pi_{t}\right)+v_{s i t} .
$$

\subsection{Empirical results}

Table 3 presents the estimates of the effect of emigration proportion on wages in the source municipalities in relation to equation (1). The first column shows the OLS estimates and the second column presents the IV estimates, where the emigration proportion is instrumented by the distance to the Belém-Teresina road by using (2).

The OLS estimate suggests that an increase of 10 percentage points in the emigration rate increases wages by $1.44 \%$ on average in each skill group. This result is substantially lower than the $3.1 \%$ reported by Mishra (2007) for Mexico, especially considering the relatively narrow standard deviation. Borjas (2003) shows that it is easier to interpret this coefficient by converting it to an elasticity that gives the percent change in wages associated with a percent change in labor supply. The wage elasticity is $0.04 \%$, evaluated at the mean value of the outmigrant supply decrease $(29.3 \%$ ), which means that a $10 \%$ supply shock (an outflow of $2.9 \%$ ) increases the wages by about $0.4 \%$.

However, when we account for endogeneity and use the distance to the road as an instrument for emigration, the estimated effect of a 10 percentage point increase in the proportion of emigrants raises wages by $5.1 \%$ (a wage elasticity of 
Table 3

Effect of emigration on wages

\begin{tabular}{lcc}
\hline & \multicolumn{2}{c}{$\ln ($ monthly earnings) } \\
\hline Proportion of emigrants in the skill group & OLS & IV \\
& $0.144^{* * *}$ & $0.510^{* * *}$ \\
& $(0.030)$ & $(0.153)$ \\
Individual characteristics & yes & yes \\
Municipality characteristics & yes & yes \\
Skill fixed effects & yes & yes \\
Year fixed effects & yes & yes \\
Interaction of skill and year fixed effects & yes & yes \\
\hline Observations & 284,506 & 284,506 \\
\hline & & First-stage \\
Distance to the road & & $-0.102^{* * *}$ \\
& & $(0.001)$ \\
First-stage F-test & Prob $>\mathrm{F}=0.0000$ \\
(instruments) & \\
\hline Observations & 284,506 \\
\hline
\end{tabular}

Note: Robust standard errors are in parentheses, clustered by interaction of skills and year and municipality. ${ }^{*}$ indicates significance at $10 \%,{ }^{* *}$ significance at $5 \%,{ }^{* * *}$ significance at $1 \%$. The dependent variable is the $\log$ of individua monthy earnings. The proportion ar emigrants in the skill group is the endogent vaiab is the log intion. dummies for marital status, a dummy for literacy, age, race, experience, squared experience, a dummy for urban residence, dummies for groups of weekly hours worked, dummies for economic sectors, and dummies for occupational position. Independent variables at the municipality level (omitted): altitude, distance to the coast (in $\log$ ), and the distances to the three state capitals (in $\log$ ) - São Luís, Teresina, and Belém. All regressions control for skill and year

fixed effects. Observations are at the individual level.
Source: Demographic Censuses (IBGE), 1980/1991.

$0.15 \%)$. Notice that the coefficient associated with the distance to the road on the first-stage regression is negative and statistically significant at the $1 \%$ significance level.

The increase in the coefficient, when comparing the OLS to the IV estimates, is similar to the findings of Mishra (2007). The author uses social networks as functions for emigration, and also finds a downward-biased OLS estimate. After considering the potential endogeneity, emigration has a large and positive effect on wages in the source municipalities.

\section{A structural approach}

In order to make it possible to estimate not only the impact of a particular emigrant flow on the wages of competing native workers, but also the cross effects on the wages of workers in different groups, we follow the structural approach presented by Card and Lemieux (2001) and Borjas (2003).

\subsection{Specification}

We assume that the aggregate production function for each municipality can be represented in terms of a two-level CES technology: workers with similar skills aggregate to form the workforce in a specific skill group and workers across skill groups then aggregate to form the workforce in each municipality over time. Formally, we have:

$$
Q_{i t}=\left[A_{i}\left(\lambda_{K_{m t}} K_{i t}^{\nu}+\lambda_{L_{m t}} L_{i t}^{\nu}\right)\right]^{\frac{1}{\nu}}
$$


where $Q_{i t}$ is the total production in each municipality over time, the $A_{i}$ represents the municipality characteristics that shift the total production, and $\nu=1-1 / \sigma_{K L}$ with $\sigma_{K L}$ is the elasticity of substitution between capital $K_{i t}$ and labor $L_{i t}(-\infty<$ $\nu \leq 1)$. The parameters $\lambda_{K}$ and $\lambda_{L}$ represent the way capital and labor are combined over time, assuming that $\lambda_{K_{m t}}+\lambda_{L_{m t}}=1$. We adopt a flexible form for $\lambda_{K}$ and $\lambda_{L}$ that allows them to vary at the micro-region level, indexed by $m$, which is a set of geographically connected municipalities defined by IBGE.

The composite aggregate workforce $L_{i t}$ is a combination of workers from different skill groups, defined as:

$$
L_{i t}=\left[\sum_{s} \theta_{s t} L_{s i t}^{\rho}\right]^{\frac{1}{\rho}},
$$

where $L_{\text {sit }}$ is the number of workers in skill group $s$, living in the municipality $i$ at time $t$, and $\rho=1-1 / \sigma_{s}$ with $\sigma_{s}$ is the elasticity of substitution across skill groups. The vector $\left(\theta_{s t}\right)$ contains the technology parameters that vary over time and shift the relative productivity of skill groups. For simplicity, we assume that $\sum_{s} \theta_{s t}=1$ and that these technology parameters are the same for all municipalities, because we are analyzing a relatively homogeneous set of municipalities.

We take the output $Q$ as the numeraire and assume perfectly competitive markets. We then substitute (4) in (3), differentiate with respect to $L_{\text {sit }}$, and take the logarithm. Thus, we have the wage of a worker in skill group $s$, living in municipality $i$, at time $t$, as given by:

$$
\begin{aligned}
\ln w_{s i t}=\ln A_{i}+\ln \lambda_{L_{m t}}+(1-\nu) \ln Q_{i t} \\
+(\nu-\rho) \ln L_{i t}+\ln \theta_{s t}+(\rho-1) \ln L_{s i t} .
\end{aligned}
$$

Substituting $\nu=1-1 / \sigma_{K L}, \rho=1-1 / \sigma_{s}$, and $\ln A_{i}=\alpha^{\prime} Z_{i}+\varepsilon_{i}$ (Card and Lemieux, 2001) equation (5) can be rewritten as:

$$
\begin{aligned}
\ln w_{s i t}=-\frac{1}{\sigma_{s}} \ln L_{s i t} & +\left(\frac{1}{\sigma_{s}}-\frac{1}{\sigma_{K L}}\right) \ln L_{i t} \\
& +\frac{1}{\sigma_{K L}} \ln Q_{i t}+\alpha^{\prime} Z_{i}+\gamma_{s t}+\gamma_{m t}+\varepsilon_{i}
\end{aligned}
$$

where $Z_{i}$ and $\varepsilon_{i}$ are the observed and unobserved components of $A_{i}$, respectively, at the municipality level; $\gamma_{m t}=\ln \lambda_{m t}$ is absorbed by interactions between period and micro-region fixed effects; and $\gamma_{s t}=\ln \theta_{s t}$ is absorbed by interactions between period and skill fixed effects.

If we assume that individuals in group $s$, municipality $i$, and period $t$ have productivity shocks in the form of $\delta^{\prime} X_{\text {sit }}^{I}+\varepsilon_{\text {sit }}^{I}$, where $X_{\text {sit }}^{I}$ represents observable characteristics of individual $I$, and $\varepsilon_{\text {sit }}^{I}$ is the random and unobserved component 
of the productivity shocks, then we have a similar equation (6) for individuals given by:

$$
\begin{aligned}
\ln w_{s i t}^{I}=-\frac{1}{\sigma_{s}} \ln L_{s i t}+\left(\frac{1}{\sigma_{s}}-\frac{1}{\sigma_{K L}}\right) & \ln L_{i t}+\frac{1}{\sigma_{K L}} \ln Q_{i t}+ \\
& +\delta^{\prime} X_{s i t}^{I}+\alpha^{\prime} Z_{i}+\gamma_{s t}+\gamma_{m t}+\varepsilon_{s i t}^{I} .
\end{aligned}
$$

\subsection{Estimation}

We now estimate equation (7) using our sample. We consider the following baseline regression:

$$
\begin{aligned}
\ln w_{s i t}^{I}=\beta_{1} \ln L_{s i t}+\beta_{2} \ln L_{i t}+\beta_{3} \ln Q_{i t} & \\
& +\beta_{4}^{\prime} X_{s i t}^{I}+\beta_{5}^{\prime} Z_{i}+\gamma_{s t}+\gamma_{m t}+\varepsilon_{s i t}^{I} .
\end{aligned}
$$

where $Z_{i}$ is a vector containing the distance to state capitals in the area (São Luis, Teresina, and Belém), altitude and distance to the coast, and $X_{s i t}^{I}$ is a vector of the same individual characteristics considered in subsection 3.2.

As in the previous section, we first estimate (8) assuming that $L_{s i t}$ is exogenous. We then take the number of workers as endogenous and use the number of emigrants $E_{\text {sit }}$ as an instrumental variable for $L_{\text {sit }}$ to estimate $\beta_{1}$. In the IV estimation, the first-stage specification is given by:

$$
\begin{aligned}
\ln L_{s i t}=\phi_{1} \ln E_{s i t}+\phi_{2} \ln L_{i t}+\phi_{3} & \ln Q_{i t} \\
& +\phi_{4}^{\prime} X_{s i t}^{I}+\phi_{5}^{\prime} Z_{i}+\mu_{s t}+\mu_{m t}+v_{s i t}
\end{aligned}
$$

where $E_{s i t}$ is the number of emigrants in group $s$, municipality $i$, and period $t$.

Table 4 presents the OLS and IV estimates of $\beta_{1}$. The OLS estimate is 0.015 , significant at $10 \%$, although the IV estimate is -0.077 , significant at $1 \%$. Again, the results indicate that the OLS is biased towards zero. The implied elasticities of substitution across types of labor for the OLS and IV are 66.67 and 12.99, respectively. These numbers are much higher than those depicted in the literature (Hamermesh, 1993). Borjas (2003) estimates elasticity of substitution across experience groups to be equal to 3.5. Similarly, the Card and Lemieux (2001) estimates for elasticity of substitution between high school and college workers range from 1.1 to 3.1 .

We can interpret these results in two ways. First, it is suggested that the technology available for the municipalities in the road area is such that workers with different levels of education and experience can be easily substituted with other workers. Second, it might be possible that the estimates of $\beta_{1}$ presented in Table 4 are biased. This bias can happen, for instance, if the migration flows are endogenous to the economic activity.

We then take one step further for the identification of the parameter $\beta_{1}$ that takes into account that $E_{\text {sit }}$ is endogenous and considers the road construction as 
Table 4

Effects of Skill Groups' Labor Supply on Earnings

\begin{tabular}{|c|c|c|}
\hline & \multicolumn{2}{|c|}{ log (monthly earnings) } \\
\hline & OLS & IV \\
\hline $\log$ (labor force in the skill group $\left(L_{\text {sit }}\right)$ ) & $\begin{array}{l}-0.015^{*} \\
(0.008)\end{array}$ & $\begin{array}{c}-0.077^{* * *} \\
(0.020)\end{array}$ \\
\hline $\log$ (labor force in the municipality $\left.\left(L_{i t}\right)\right)$ & $\begin{array}{c}-0.056^{* * * *} \\
(0.019)\end{array}$ & $\begin{array}{c}0.004 \\
(0.026)\end{array}$ \\
\hline $\log \left(\mathrm{GDP}\right.$ in the municipality $\left.\left(Q_{i}\right)\right)$ & $\begin{array}{c}0.124 * * * \\
(0.014)\end{array}$ & $\begin{array}{c}0.126^{* * * *} \\
(0.014)\end{array}$ \\
\hline Individual characteristics & yes & yes \\
\hline Municipality characteristics & yes & yes \\
\hline Interaction of skill and year fixed effect & yes & yes \\
\hline Interaction of micro region and year fixed effect & yes & yes \\
\hline Observations & 284,509 & 284,509 \\
\hline $\log$ (total number of outmigrants) & & $\begin{array}{c}\text { First-stage } \\
0.370^{* * *} * \\
(0.002)\end{array}$ \\
\hline $\begin{array}{l}\text { First-stage F-test } \\
\text { (instruments) }\end{array}$ & & Prob $>\mathrm{F}=0.0000$ \\
\hline Observations & & 284,509 \\
\hline
\end{tabular}

Note: Robust standard errors are in parentheses, clustered by interaction of skills and year and municipality. * indicate significance at $10 \%, * *$ significance at $5 \%, * * *$ significance at $1 \%$. The dependent variable is individual monthly earning $(\mathrm{ln})$. The endogenous variable in the IV estimation is the labor force in each skill group. Independent variables at the individual level (omitted): gender, a dummy indicating migrants, years of schooling, dummies for marital status, dummy for literacy, age, race, experience, squared experience, a dummy for urban residence, dummies for groups of weekly hours worked, dummies for economic sectors, and dummies for occupational position. Independent variables a the municipality level (omitted): altitude, distance to the coast (in $l o g$ ), and the distances to the three state capital (in log) - São Luis, Teresina, and Belém. All regressions control for skill and year fixed effects. Observations are a

an additional source of identification. We specify another equation for $E_{\text {sit }}$ given by:

$$
\begin{aligned}
\ln E_{\text {sit }}=\delta_{1} \ln D_{i}+\delta_{2} \ln L_{i t}+\delta_{3} \ln Q_{i t} & \\
& +\delta_{4}^{\prime} X_{s i t}^{I}+\delta_{5}^{\prime} Z_{i}+\varphi_{s t}+\varphi_{m t}+v_{s i t},
\end{aligned}
$$

where $D_{i}$ is the linear distance between the administration center of the municipality and the nearest point on the road.

Table 5 presents the estimates obtained from a three-step estimation procedure that uses equations (8), (9), and (10). Again, results suggest that endogeneity potentially biases the estimation towards zero. The $\beta_{1}$ estimate changes substantially to -2.863 , significant at $5 \%$, which indicates a lower elasticity of substitution across skill groups (or types of labor) of 0.35 . This number is quite different from the other estimates available in the literature (Hamermesh, 1993). However, it is important to keep in mind that our sample is comprised of individuals with extremely low levels of education. According to Table 1, only $13 \%$ of non-migrants have five or more years of education. The estimated elasticity of substitution across groups might reflect the difficulty in substituting individuals across education and experience groups in this less educated population.

The elasticity of substitution between capital and labor, $\sigma_{K L}$, can be obtained from $\beta_{2}$ (based on $\beta_{1}$ ) or $\beta_{3}$. In Table 5 , both ways of computing $\sigma_{K L}$ lead 
Table 5

Estimated elasticity of substitution across skill groups

\begin{tabular}{|c|c|c|c|}
\hline & $\begin{array}{c}\log \\
\text { (earnings) }\end{array}$ & $\begin{array}{c}\log \\
\text { (labor force) }\end{array}$ & $\begin{array}{c}\log \\
\text { (outmigrants) }\end{array}$ \\
\hline $\log$ (labor force in each skill group) & $\begin{array}{c}-2.863^{* *} \\
(1.348)\end{array}$ & & \\
\hline $\log$ (emigrants in each skill group) & & $\begin{array}{c}0.067^{* * *} * \\
(0.026)\end{array}$ & \\
\hline Distance to the Belém-Teresina road & & & $\begin{array}{c}-0.222^{* * *} \\
(0.007)\end{array}$ \\
\hline $\log$ (labor force in each municipality) & $\begin{array}{c}2.701^{* *} \\
(1.304)\end{array}$ & $\begin{array}{c}0.918^{* * *} \\
(0.019)\end{array}$ & $\begin{array}{c}0.727^{* * * *} \\
(0.004)\end{array}$ \\
\hline $\log$ (GDP in each municipality) & $\begin{array}{c}0.189 * * * \\
(0.032)\end{array}$ & $\begin{array}{c}0.002 \\
(0.008)\end{array}$ & $\begin{array}{c}0.314^{* * *} \\
(0.003)\end{array}$ \\
\hline Individual characteristics & yes & yes & yes \\
\hline Municipality characteristics & yes & yes & yes \\
\hline Interaction of skill and year fixed effects & yes & yes & yes \\
\hline Interaction of microregion and year fixed effects & yes & yes & yes \\
\hline Observations & 284,509 & 284,509 & 284,509 \\
\hline
\end{tabular}

Note: Robust standard errors are in parentheses. $*$ indicates significance at $10 \%, * *$ significance at $5 \%, * * *$ significance at $1 \%$. Independent variables at the individual level (omitted): gender, a dummy indicating migrants, years of schooling, dummies for marital status, a dummy for literacy, age, race, experience, and squared experience, a dummy for urba residence, dummies for groups of weekly hours worked, dummies for economic sectors, and dummies for occupational distances to the three state capitals (in log) - São Luís, Teresina, and Belém. All regressions also control for skill and year fixed effects. Observations are at the individual level.

Source: Demographic Censuses (IBGE), 1980/1991.

to statistically equal values. Considering the computation from $\beta_{3}$, we see that $\hat{\sigma}_{K L}=5.3$. It is a high value when compared to the empirical evidence found in the international literature, which ranges from 0 to 1.5. Among the results reported by Hamermesh (1993), only Hall et al. (1990) estimate a value with the same order of magnitude -6.86 for the United Kingdom. Again, we can explain the high elasticity of substitution between labor and capital by the labor market conditions in the region around the Belém-Teresina road, where workers have low levels of education and are therefore easily substituted with capital (Cahuc and Zylberberg, 2004).

\subsection{Simulations of the Effects of Emigration on Wages}

Following Borjas (2003), we estimate the impact of the migration outflows on wages in the municipalities of the Belém-Teresina road area by keeping capital stock constant. In this case, the total effect is a combination of the own-factor price elasticity, $\varepsilon_{s i, s i}$, and the cross-factor price elasticity, $\varepsilon_{s i, s^{\prime} i}$, given by:

$$
\Delta \ln w_{s i}=\varepsilon_{s i, s i}\left(-m_{s i}\right)+\sum_{s^{\prime} \neq s} \varepsilon_{s i, s^{\prime} i}\left(-m_{s^{\prime} i}\right)
$$

where $m_{s i}$ is the average emigration rate for the years 1980 and 1991 of the skill group $s$ in municipality $i$. The negative sign stands for the reduction in the labor supply induced by emigration. 
Hamermesh (1993) and Borjas (2003) point out that the factor price elasticity keeps marginal cost and quantities of other factors constant. Thus, the own-factor price elasticity can be obtained by deriving equation (5) from the logarithm of total labor in skill group $s$, in municipality $i\left(\ln L_{s i}\right)$, which gives us:

$$
\varepsilon_{s i, s i}=(1-\nu) \frac{d \ln Q_{i}}{d \ln L_{s i}}+(\nu-\rho) \frac{d \ln L_{i}}{d \ln L_{s i}}+(\rho-1) .
$$

We can rewrite the equation (12) as a function of the estimated elasticities of substitution and the shares of income assigned to each group:

$$
\varepsilon_{s i, s i}=\frac{1}{\sigma_{K L}} s_{s i}+\left(\frac{1}{\sigma_{s}}-\frac{1}{\sigma_{K L}}\right) \frac{s_{s i}}{s_{L}}-\frac{1}{\sigma_{s}},
$$

where $s_{s i}=\frac{d \ln Q_{i}}{d \ln L_{s i}}$ is the share of income assigned to group $s$, in municipality $i$, and $s_{L}=\frac{d \ln Q_{i}}{d \ln L_{i}}$ gives the labor's share of income in municipality $i$.

Similarly, the cross-factor price elasticity is given by:

$$
\varepsilon_{s i, s^{\prime} i}=\frac{1}{\sigma_{K L}} s_{s i}+\left(\frac{1}{\sigma_{s}}-\frac{1}{\sigma_{K L}}\right) \frac{s_{s^{\prime} i}}{s_{L}} .
$$

Notice that both the own-factor price and the cross-factor price elasticities vary across skill groups and municipalities. The income shares $s_{s i}$ and $s_{L}$ were obtained from the earnings reported in the 1991 Census and from the GDP information used above.

Table 6 reports the mean, the minimum, and the maximum of the own-factor and cross-factor price elasticities estimated for each municipality. The overall average of the own-price elasticity is -2.62 , and indicates that a reduction of $10 \%$ in the labor force increases wages by $26.2 \%$. Numbers across groups are quite homogeneous. It seems that most of the variation occurs between municipalities.

The estimated cross-factor elasticities, or elasticities across types of labor, are much lower and positive, similar to those found by Borjas (2003). The overall average cross elasticity is 0.2428 and suggests that a reduction in the number of workers in one group implies an average increase in wages of $2.4 \%$. The variation across groups is high. Groups of individuals with less experience have systematically lower cross-factor price elasticities. The same is true for education, although with less intensity.

Table 7 describes the emigration shocks, $m_{s i}$, and the total wage effects determined by (11). Emigration is quite intensive for groups with one to five years of experience and less than one, one to four, or five or more years of schooling, with averages of $86 \%, 123 \%$, and $110 \%$, respectively.

The estimated average wage effect indicates that the migration outflows induced by the road construction increased wages in the source municipalities by $51.5 \%$. This is a very high effect in absolute terms, but has the same magnitude 


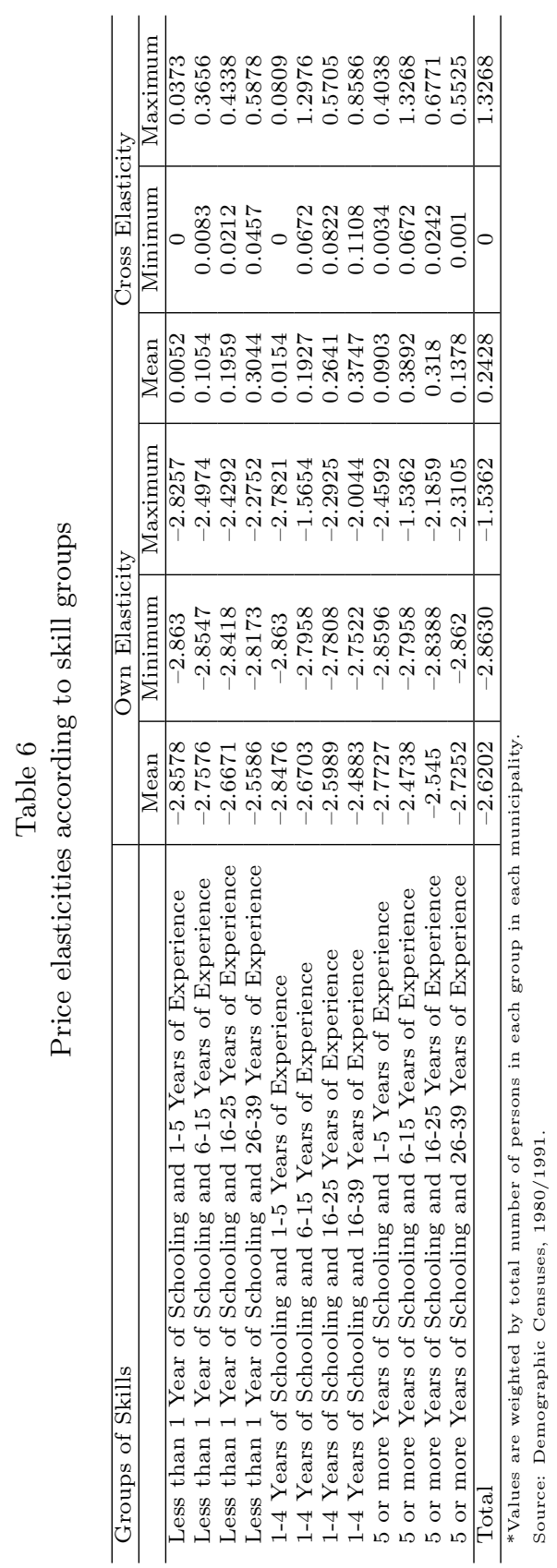




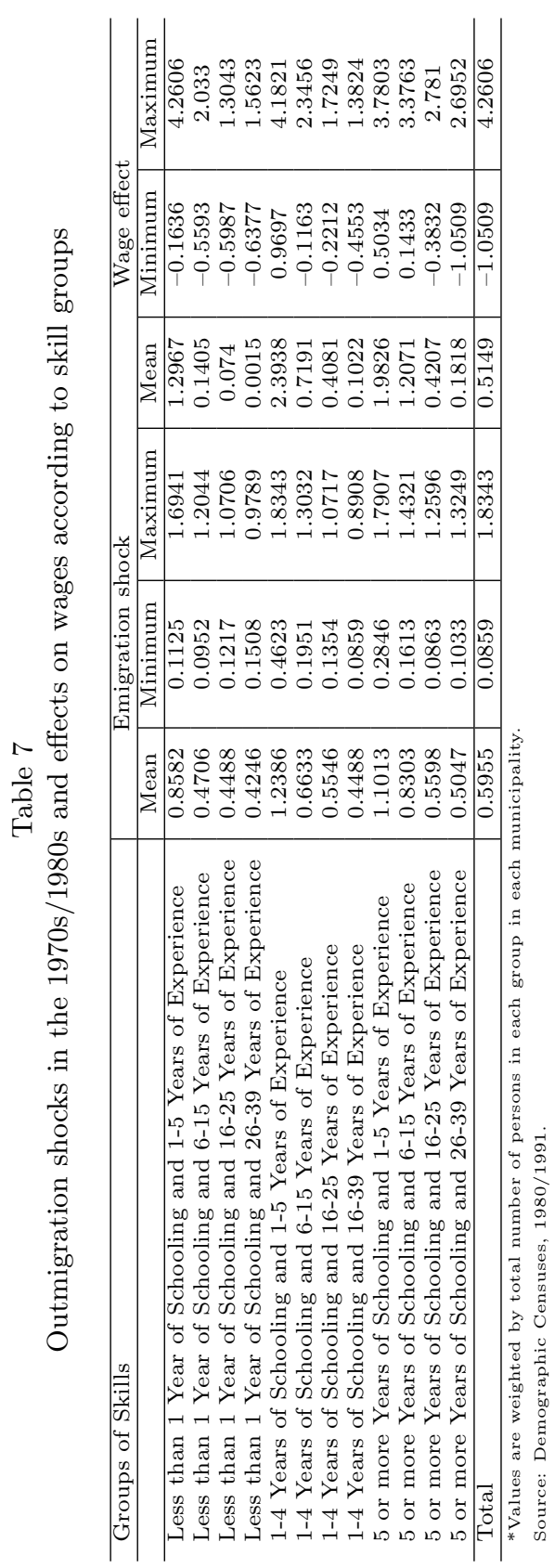


of the average emigration rate of $60 \%$. We must emphasize that this high mobility could be explained by the age structure of the regional population - a very young workforce; on average, the workers in the municipalities located near the road were 23-24 years old (Table 2).

On the other hand, the wage effect is highly heterogeneous, ranging from $105 \%$ to $426 \%$. The heterogeneity of the emigration shocks and of the wage effects is also depicted in Figure 6. In most of the cases, the wage effect is positive, indicating that the substitution effect is larger than the complementary one. However, the wage effect is negative for some skill groups in some municipalities in which the complementary effect is large. This is especially true for the groups with 26 to 39 years of experience, which face a relatively low migration outflow and are affected by the changes in other groups.

When we average the wage effects by municipalities, all the negative effects disappear. The distribution of the effects is presented in Figure 7. At the municipality level, the average wage effects range from $15.6 \%$ to $143.6 \%$, with a large concentration around the mean $56 \%$. Figure 8 shows how the wage effect varies with the distance to the Belém-Teresina road, at the municipality level. The magnitude of the final effect varies significantly with respect to the distance to the road. Municipalities closer to the road experience a higher migration shock, as shown by Figures 4 and 5 and, consequently, a higher wage effect.

\section{Caveats and Limitations}

The analysis of the previous sections is based on the assumptions that the road construction has affected the labor supply in the municipalities in a $200-\mathrm{km}$ radius through a migration outflow of workers, and that there is no other relevant link between the road construction and wages. One of the potential pitfalls in these assumptions is related to the impact of the new road on business and on the location of firms. It might be the case that the pattern depicted in Figure 8, in which the wage effect declines with the distance to the Belém-Teresina road, is determined by an improvement in the labor demand in the areas closest to the road.

Although we cannot assure that the exclusion condition stated above is valid for our case, we do have some evidence that the road construction has affected the labor supply more intensely than the labor demand. The underlying assumption is that labor is more mobile than capital. Figure 9 shows how the number of firms and the value of the residential capital stock varies with the distance to the Belém-Teresina road.

Neither the levels nor the changes in the number of firms or the stock of residential capital seem to decline with the distance to the road. The number of firms has a flat pattern that has remained the same throughout the years. Thus, if the wage effects estimated in the previous sections are generated by changes in labor demand, then they are generated by other mechanisms which are not 
Figure 6

Emigration shocks, wage effects, and skill groups

Distribution of the out-migration rate (within and across groups)

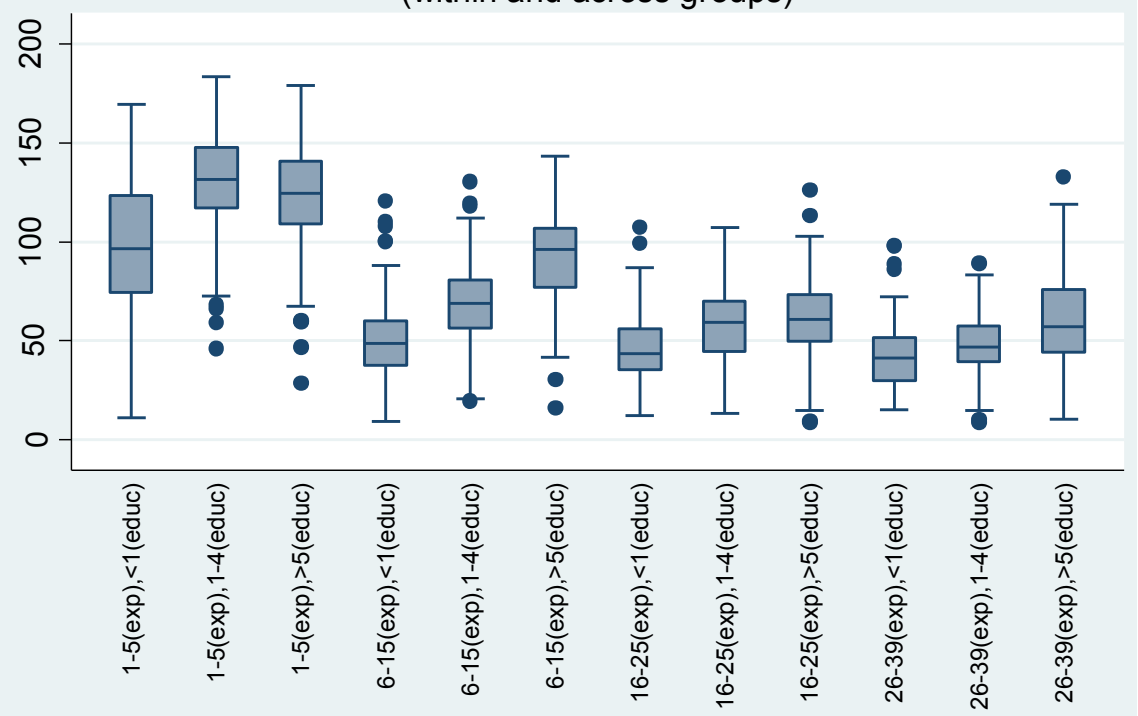

Distribution of the wage effect (within and across groups)

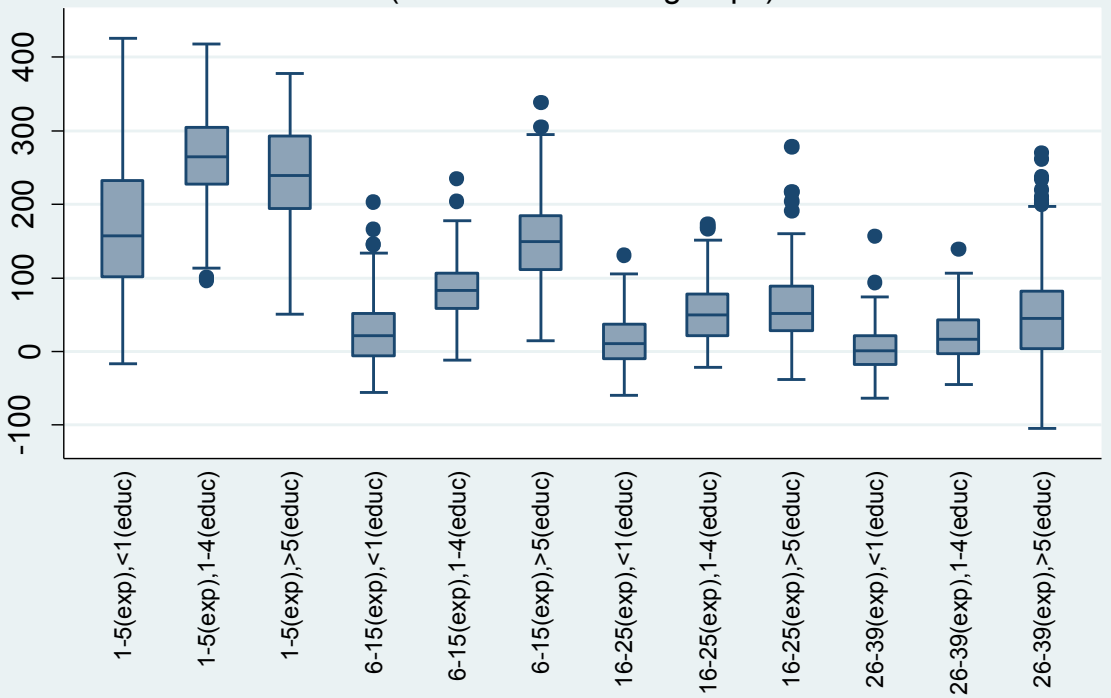

Source: Author's estimates based on Demograpic Census of 1980 and 1991. 
Figure 7

Distribution of the wage effects across municipalities

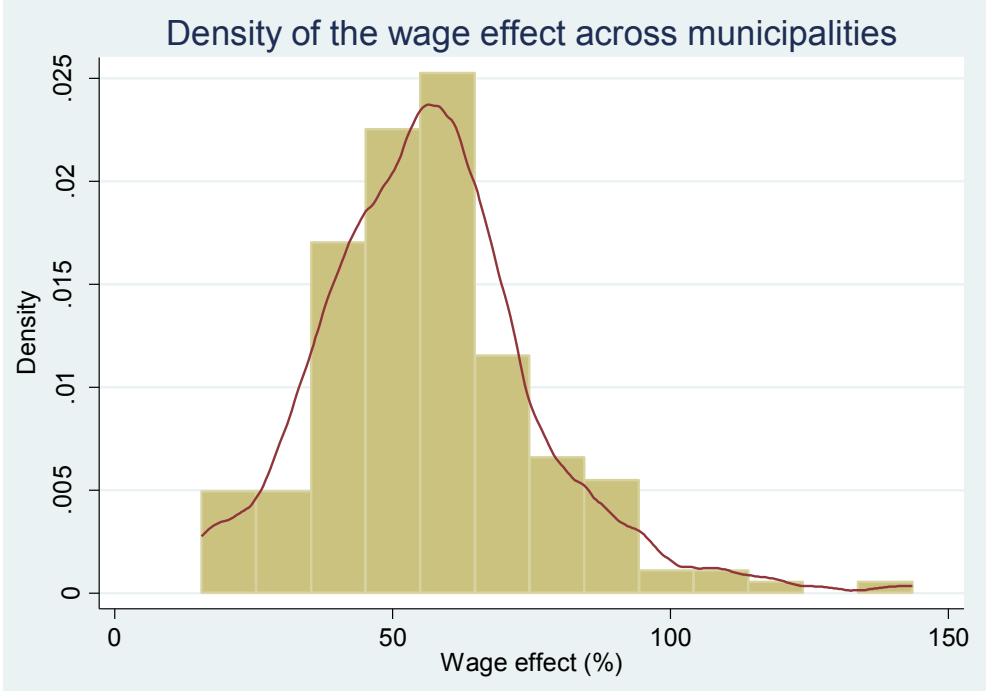

Source: Author's estimates based on Demographic Census of 1980 and 1991.

Figure 8

Wage effect and distance to the Belém-Teresina road

Wage effect and distance to the Belém-Teresina road

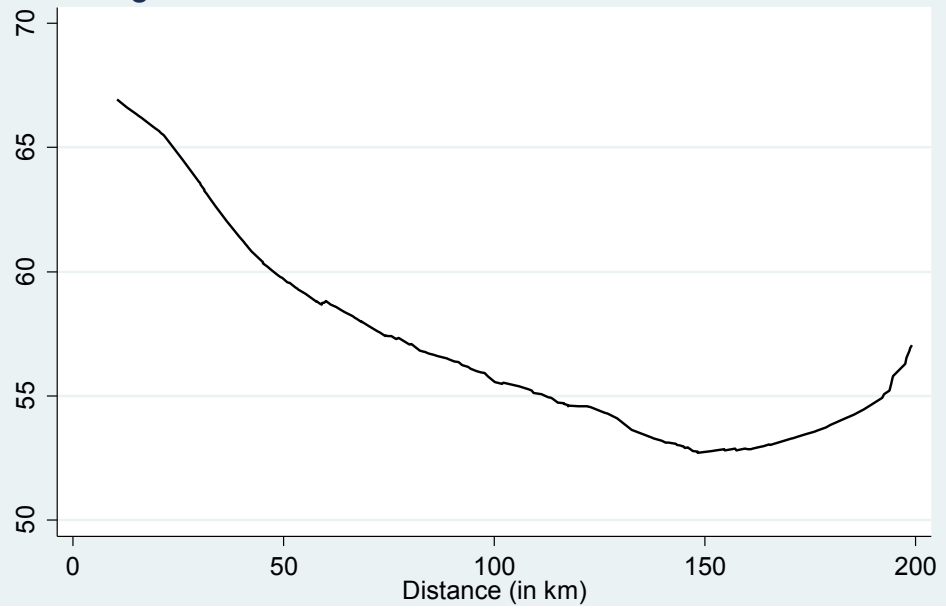

Source: Demographic Census of 1980 and 1991. 
related to the number of firms. The pattern of the residential capital points in a similar direction.

\section{Conclusion}

This paper investigates the impact of road construction on labor markets in municipalities located within an area of a 200-km radius from the Belem-Teresina road. We have shown that the road construction has changed the population distribution in the area - many towns were created along the road and there was an increase in migration flows within the area.

Following a strucutural model approach, we use migration outflows as a source of variation in labor supply in order to estimate elasticity of substitution across skill groups (or types of labor) and elasticity of substitution between capital and labor. We also consider the distance to the road as an instrument for emigration. Then, based on the estimates of elasticities of substitution across types of labor and between capital and labor, we calculate the own-factor and cross-factor price elasticities of labor demand across skill groups. Finally, by considering these factor price elasticities and the observed emigration shocks, we show the wage effects of the Belém-Teresina road construction.

The results suggest that the migration outflows determined by the road construction have important consequences for the municipalities that lose workers. The episode has produced an overall increase of $50 \%$ in wages, although we also document a reduction in wages in some skill groups in some municipalities due to complementary effects. 
Figure 9

Number of firms, residential capital, and distance to the Belém-Teresina road

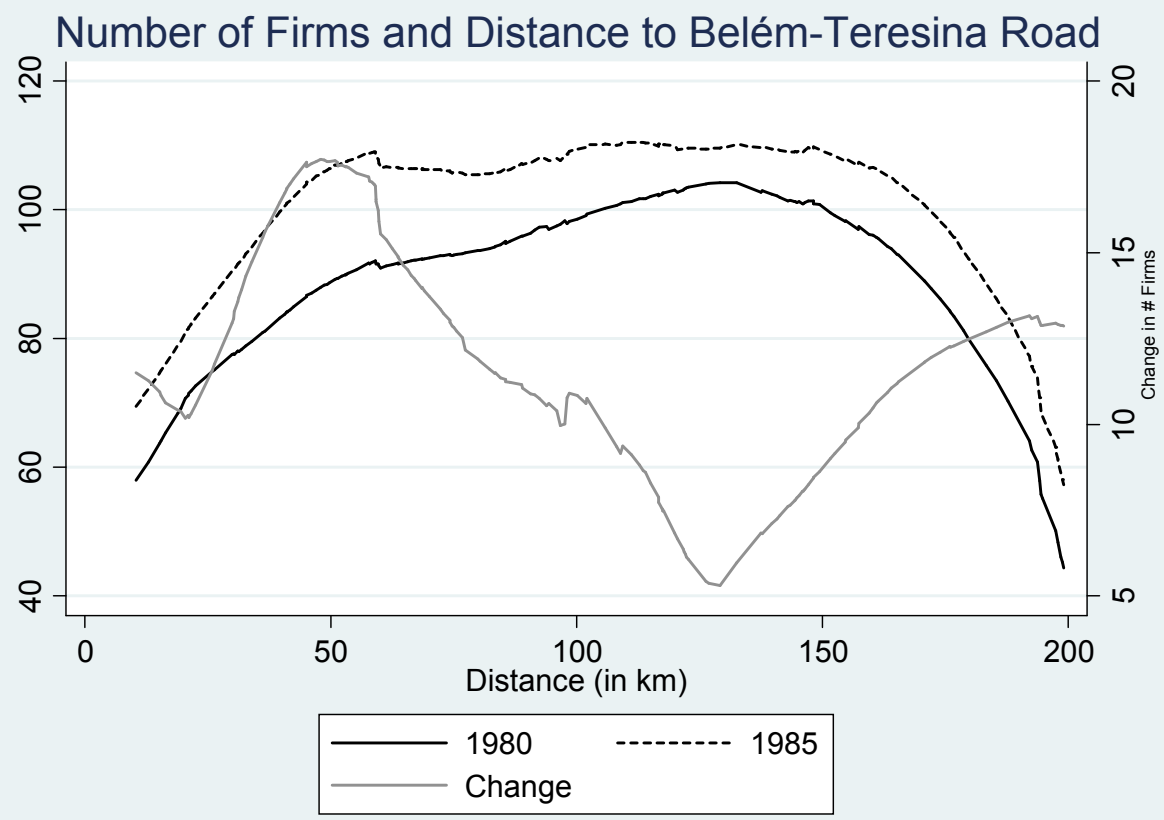

\section{Residential Capital and Distance to Belém-Teresina Road}

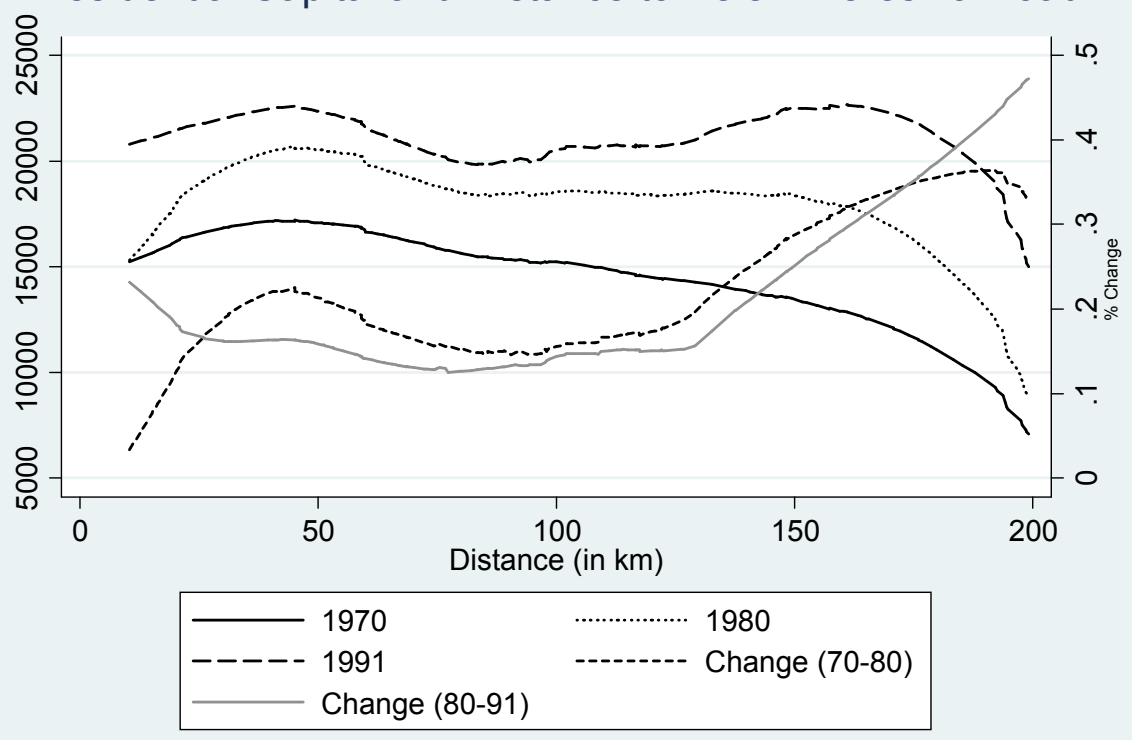

Source: IPEADATA. 


\section{References}

Banerjee, B. \& Kanbur, R. (1981). On the specification and estimation of macro rural-urban migration functions: with an application to Indian data. Oxford Bulletin of Economics and Statistics, 43:7-30.

Baum-Snow, N. (2007a). Did highways cause suburbanization? Quarterly Journal of Economics, 122:775-805.

Baum-Snow, N. (2007b). Suburbanization and transportation in the monocentric model. Journal of Urban Economics, 62:405-423.

Borjas, G. J. (1987). Self-selection and the earnings of immigrants. American Economic Review, 77:531-553.

Borjas, G. J. (1999a). The economic analysis of immigration. In Ashenfelter, O. \& Card, D., editors, Handbook of labor economics. Elsevier Science; North-Holland, Amsterdam.

Borjas, G. J. (1999b). Heaven's door: immigration policy and the American economy. Princeton University.

Borjas, G. J. (2003). The labor demand curve is downward sloping: reexamining the impact of immigration on the labor market. Quarterly Journal of Economics, 118:1335-1374.

Cahuc, P. \& Zylberberg, A. (2004). Labor economics. MIT, Cambridge, Mass.

Card, D. \& Lemieux, T. (2001). Can falling supply explain the rising return to college for younger men? Quarterly Journal of Economics, 116:705-746.

Carrington, W., Detragiage, E., \& Vishwanath, T. (1996). Migration with endogenous moving costs. American Economic Review, 86:909-930.

Chiquiar, D. \& Hanson, G. H. (2005). International migration, self-selection, and the distribution of wages: evidence from Mexico and the United States. Journal of Political Economy, 113:239-281.

Chiswick, B. R. (1978). The effect of americanization on the earnings of foreignborn men. Journal of Political Economy, 86:897-922.

Chiswick, B. R. (1999). Are immigrants favorably self-selected? American Economic Review, 89:181-185.

Duranton, G. \& Turner, M. A. (2007). Urban growth and transportation. Working Paper 305, Department of Economics, University of Toronto. 
Fields, G. S. (1979). Place-to-place migration: some new evidence. Review of Economics and Statistics, 61:21-32.

Greenwood, M. (1975). Research on internal migration in the United States: a survey. Journal of Economic Literature, 13:397-433.

Hall, S. G., Henry, S. G. B., \& Pemberton, M. (1990). Testing a discrete switching disequilibrium model of UK labour market. Discussion papers 28, Bank of England, London.

Hamermesh, D. S. (1993). Labor demand. Princeton University, New Jersey.

Kanbur, R. \& Rapoport, H. (2005). Migration selectivity and the evolution of spatial inequality. Journal of Economic Geography, 5:43-57.

Mckenzie, D. \& Rapoport, H. (2007). Network effects and the dynamcis of migration and inequality: theory and evidence from Mexico. Journal of Development Economics, 84:1-24.

Michaels, G. (2008). The effect of trade on the demand for skill evidence from the interstate highway system. Review of Economics and Statistics, 90:683-701.

Mishra, P. (2006). Emigration and brain drain: evidence from the Caribbean. Working papers 06/25, IMF, Washington, DC.

Mishra, P. (2007). Emigration and wages in source countries: evidence from Mexico. Journal of Development Economics, 82:180-199.

Morten, M. \& Oliveira, J. (2013). Labor market integration in Brazil. In LSE/UCL Devo Seminar.

Morten, M. \& Oliveira, J. (2014a). The long-run effects of roads: Evidence from planned capital cities. Unpublished.

Morten, M. \& Oliveira, J. (2014b). Migration, roads and labor market integration: Evidence from a planned capital city. In Brazilian Meeting of Econometrics, Natal.

Roy, A. D. (1951). Some thoughts on the distribution of earnings. Oxford Economic Papers, 3:135-146.

Sahota, G. S. (1968). An economic analysis of internal migration in Brazil. Journal of Political Economy, 76:218-245.

Sant'anna, J. A. (1988). Rede básica de transportes da amazônia. Texto para Discussão 562, IPEA, Brasília, DF. 
Schwartz, A. (1973). Interpreting the effect of distance on migration. Journal of Political Economy, 81:1153-1169.

Sjaastad, L. A. (1962). The costs and returns of human migration. Journal of Political Economy, 70:80-93. 